form

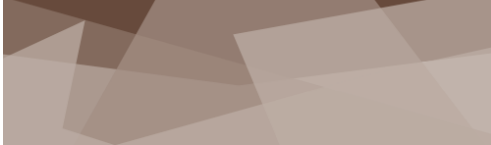

Vol I4, No 4 (202I) https://doi.org/10.7577/formakademisk.4638

Liv Mildrid Gjernes

Professor

Western Norway University of Applied Sciences, Norway liv.mildrid.gjernes@hvl.no

\title{
Aarup 1960 and the poetics of materials ${ }^{1}$
}

\begin{abstract}
All design has its own conditional modes of expression; however, these are realised through the maker's sense of the possibilities of materiality. This essay was inspired by a reclaimed piece of 1960s furniture designed in the modernist idiom, and is based upon autobiographical experiences, original works from own and contemporary aesthetic practices, and associated thoughts in the present. A completely new artistic expression was developed, which questioned the strict, use-defined style ideals and let shape reveal other values and statements than function. The intention of this essay is to put into words some of the cognitive processes in which creativity, critical reflection and the senses' experience-based insights may bring up something new. In creative work, the goal is not to reach a single result; every little discovery made by examining something specific could open up new worlds.
\end{abstract}

Keywords:

materials, modernism, post-modernism, meaning, arts based.

The concept of modernity refers to an era that can be said to begin in the Renaissance, writes the philosopher Lars Fr. H. Svendsen in his book Kunst, en begrepsavvikling [Art, a concept settlement] (Svendsen, 2000). He further explains how the style period of modernism began towards the end of the nineteenth century and continued into the twentieth. Modernism represents the age of reproduction and a continuation of the age of technology. As a style expression, it grew from a reaction to the romantic and quirky forms of expressions that had emerged towards the turn of the previous century. Industrialisation, machine technology and rational form developed as a contrast to the swirly, handcrafted and romantic expressions of pre-modernism, which also accommodated the popular, pre-industrial visual expressions. "Post" means after. According to Svendsen, the age-after-modernism began as the Second World War ended. Even throughout the 1960s, an incipient postmodernism was developing within art, architecture and design simultaneously as honest and factual objects of modernism were finding their way into many homes. 
During this time, purist and cutting-edge opinions were formed by artists and designers. In this manner, one can detect how the style periods infiltrated each other. In retrospect, looking into the interpretations and retellings the style periods appears purist. Materials, colours, size and structures are used as elements in idioms that reveal our time. Postmodernism problematized modernist values and forms of expression by moving from one extreme to another. It recalled memories and allegations of the content of expressions that modernism, in its time, had dismissed as impure, ugly and seedy; ornaments merely regarded as decoration without purpose, or expressions of a criminal mind, which the Swiss architect Adolf Loos (1870-1933) stated in his lecture Ornament und Verbrechen in 1910 (Adolf Loos, 1908).

Svendsen further explains how the distinctive features of modern times developed through "quotations" or imitations. Ornaments and decorations were re-adopted by borrowing from earlier times, manufacturers and artists. "Images that primarily refer to other images," as Svendsen refers to them (2000, p. 102). He writes about appropriations where the artist makes everything contemporary by adding their own work to part of the expression or by recreating an old motif through photography or paint. Dag T. Andersson justifies imitation or "mimesis" as "the force in all forms of play", and argues that "the mimetic urge" is expressed through our artistic activities (2001, p. 34). In this manner, the idioms of previous times were brought back, played with and re-examined in postmodernism.

"The basic features of the mimetic relationship to things is perhaps most apparent in craftsmanship," writes Andersson. The methods of craftsmen are closely related to those of the artists. This clearly shows how a mimetic relationship involves reciprocity between man and things. The craftsman recognises the material's right to find its place through the object's shaping. The material may retain its remoteness even if it is transformed by the way the hand's work brings it closer (2001, p. 34).

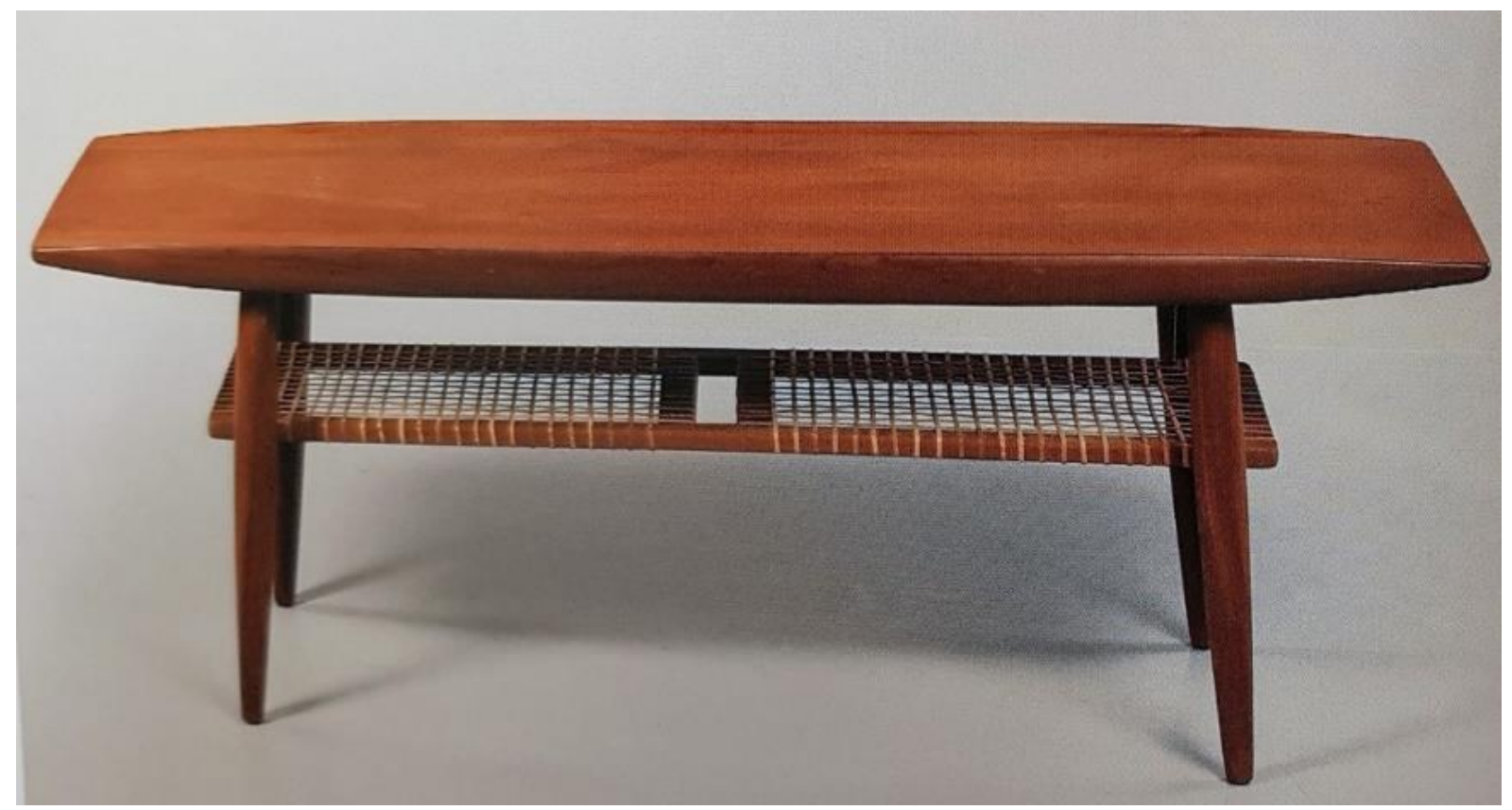

FIGURE 1. Aarup. Produced for IKEA in 1960. Source: Siesing, A. (2015, p. 410), (C) Bukowski Auktioner AB.

I remember the 1960s. I experienced how saving materials and anything that could be saved was both normal and necessary. The 1960s still reflected the scarcity of materials after the war, with refashioned clothes and worn-out rubber boots. We put newspaper in our rubber boots in the winter to try and protect our feet from the cold. But since the boots were full of holes from being used by older siblings, the wet and icy cold seeped into our toes anyway. IKEA was already in business and developing sensible and down-to-earth furniture for the average socially democratic family. The quality of their products 
must have been something completely different to what it is today, as their range included the Aarup coffee table: a wonderful 1960's idol (Figure 1).

"Aarup is one of the finest pieces of Danish-made furniture produced in Sweden exclusively for IKEA. It has a quality of the construction, with lavish and rounded mouldings, solid undercarriage, and a newspaper shelf of braided rattan" read its advertisement (Siesing, 2015, p. 410).

Materials such as rattan and teak were used previously in modernism but in a completely different, simple and poetic manner, with small leaps, elongated arches and softly rounded corners. When combined, these features resulted in something tight and elegant. With this design, the production costs went down, and the object was made available to most socially democratic people. According to Svendsen, modernity is about the abolition of traditions. Wretched old things that the war hadn't finished off were finally thrown away or burned, everything reminiscent of hand-me-downs, worn-out shoes and walking home along long, winding roads. Norway was one of the poorest countries in Europe before the war. There were no busses or cars, only the high heavens and bitter cold. In my childhood home, we took nothing for granted. Internalised traditions of farming culture from the past was combined with pastel colours and modern checker tiles in the kitchen. New elements were added to "Iydarmusikken"2, which flowed from the Hardanger fiddles' mysterious, eternal tones.

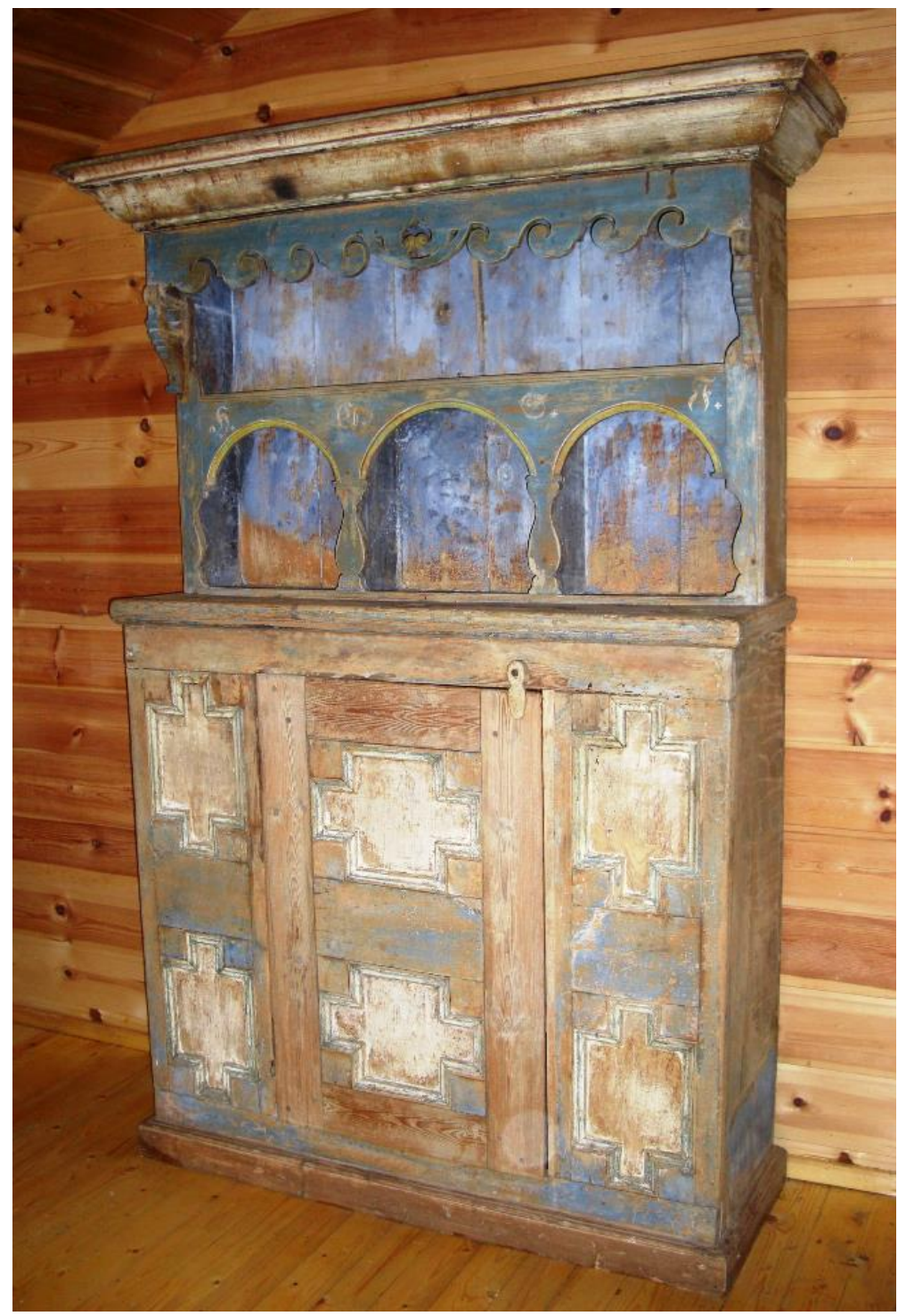

FIGURE 2. Excample: 18th century front cabinet. Source: private collection and photo. Source: private collection. Photo: Håvard Gjernes. 
The eighteenth-century front cabinets became the inspiration for newer interpretations of more front cabinets (Figure 2). The last three variations were made by my father for my sisters-in-law and my sister in the 1990s. My aunts painted them in vibrant colours and this furniture lives on between us in a profound and old happiness with its families. I was given a reproduction of one from the 1960s and it stands here, looming in heavy, Norwegian birch. The angular, stout and stabile structure, with its roots in times long past, casts a reserved sidelong glance at the swanky table, which bravely attempts to assert itself with its tropical woods.

This old table was restored before it ended up in the second-hand market. The tabletop is veneered with the finest teak, but if you take a closer look, you can see that it looks as though the construction is made of pine and stained with a teak-imitating colour. The look-alike-materials are chosen from exquisite subjects and the coniferous, edge-cut winter wood creates a pattern that can be mistaken for teak's sturdy, exotic wood grain designs. Take that, modernism! This piece of furniture pretending to derive from pure, exotic, imported wood is only a home-made interpretation of the real thing. The everyday pine wood board had to do the job once again. Yet, I forgive you little old table, because it's the form and shape that carries an object through time, and whether the materials are authentic is of minor importance. I must admit that I could be willing to drive far for an original 1960s Aarup from IKEA, one made from solid teak and real rattan, weighing $13 \mathrm{~kg}$. Aarup was a rock solid, honest, industrial product, and its massive tabletop could have been sanded and oiled again and again. Perhaps one of them is waiting in a Swedish basement somewhere, longing to become real again. However, I can appreciate the aesthetics of necessity, and the notion of saving where possible, especially when creating something new. The swanky table is a design that has been imitated. It's a reproduction, a style-copy, whereas a 1960s Aarup was a role model. The only new aspect is the pine masquerading as teak. Skimping is skimping and that is okay. Why use valuable tropical wood when the whole thing can be recreated using home-grown pine from the shops? The understanding of art and the term "aesthetics" has changed since the second world war. Art is no longer unambiguous and true, and Svendsen explains how this has been phased out. He dismisses the notions of "true and divine", which had been understood and decided throughout all of modernism, and instead gives the power of the definition to the interpreter (2000, p. 25).

In 1936, the German philosopher and art theorist Walter Benjamin (1892-1940) published an essay called, Art in the age of reproduction (Das Kunstwerk im Zeitalter seiner technischen Reproduzierbarkeit). In this text, he highlights the circumstances of the human experience, when technology sets the premises. Benjamin used the term "aura" in his explanation of the relationship man has to things, which the philosopher Dag T. Andersson writes about in his book, Tingenes taushet, tingenes tale (2001). Aura expresses an aesthetic relationship between man and things, between man and the world, in the way that there are relationships that do not concern the arts alone but any sensory relationship to things, he writes (2001, p. 32).

Since the second half of the last decade, the circumstances for the material-specific, man-made objects have changed completely. However, our sensory relationship to things and their nature still lives in our encounters with them. All knowledge of the practical and living life rests in the human experience. In this manner, our worlds are built from our childhood and manifest themselves in a conglomerate of sensations, memories and experienced knowledge. We try and fail, perhaps by imitating what seems to be there; we copy and imitate, and examine and play with the possibilities in the attempt to get as close as possible to the nature of things, or "aura". Gradually we find the courage and insight to interpret the language of things, as we ourselves understand it. Ideals of different times frame our possibilities. Time opens up or limits our possibilities. It ties itself together with the act of existing, experiencing and conveying the world as we see it.

We express ourselves in everything we make and design, not just in what we articulate verbally or in text. This is why it is so important to design or make things in a close, analogue and one-to-one way. All things, all buildings and surroundings, say something about the spirit of time as it has been experienced, interpreted and told by the individuals that were present. Everything is there, still accessible for new experiences and interpretations. Through our personal and perceptual relationships, we bring everything into our world. How do we experience what has no name, that is to say, that which 
is primarily experienced as definite? Knut Ove Eliassen asks in his essay "Tingenes tale" [The speech of things] (2008). He writes about how Foucault thematises "what we can call the meeting of 'things', meaning the experience and naming of them, but also our own experience and naming that through such meetings are made possible" (2008, p. 174). Bård Breivik (1948-2016) was an inspiring, contemporary artist from Bergen. He referred to his own specific experiences behind his meeting with the work he presented in public space in a lively way. As a sculptor, or maker, he concerned himself with matters of materiality and man-made. The use of organic materials exposes a human and cultural intelligence, he said in an interview in 2015 (Landro, 2016, p. 947). The poetry of materials lives in his understanding of intelligence.

For the designer, the artist or maker, material-based work and the sensory relationship to things drives the process. The senses interpret the materials through the sound of a sharp wood planer, the tactility of processing a surface, the scent of an oiled shape. You experience a storyline of expression possibilities, which make themselves known and become concrete and understood, supported by the process that shapes them. Conditioned by our sensory relationships to things and the materials they consist of. We search for our things, we thoughtfully draw and sketch, always looking for something precise, for the result of our investigations into what is real and sensory to us; the definite. A careful process revolving around the realisation of inner imagination, made tactile and visible in physical materials.

In the craft of making furniture, the veneer was intended as a way to cut costs. My table is an example of this: the top was intentionally disguised to look as if it was made of teak, while in reality, it is only covered by a thin layer. This layer is glued on a core of some cheap, yet stable material. Veneer is a thin layer of wood, often 'sliced' off the tree-trunk, as one would peel a potato, in long strips down the length of the tree. The strips are then cut into suitable sizes for transport purposes and manageability. Under the finished veneered surfaces is a layer to ensure an even and stable surface. The second outer layer might be plywood, a very sturdy material made from gluing thin wood together, like 'layers' in Photoshop, but in alternating directions. Between these two layers, there might be pieces of wood lamellae lying next to each other, which defines the thickness of the board and is solidly glued to both the top and bottom layer. The reason the wood veneer is glued on is that it must be stable as the wood itself is unstable and hygroscopic. The material lives in the humidity of its surroundings and the cells of the wood absorb or release moisture, resulting in shrinkage or swelling. A newly cut pine board can shrink up to ten per cent. One of the challenges of working with solid wood is that the material continues to live on after it is cut and prepared. Wood craftsmanship has developed all sorts of methods and ways to use and exploit these characteristics. For example, a stile door is built with consideration of this, with tracks in the frames for the panels to sit in, so the wood has space to move according to its nature without bursting the frame apart. It is a respectful way of communicating with the material; no force and nothing falsified. The material is allowed to be what it is.

Insight into the possibilities of a craft and its ways of communication gives us the freedom to move closer towards materials and the aura of things. Treading hard on modernism's clean, purist toes was a strong need for those who came after it. With technical competence, we could make diverse and uncensored re-interpretations. We just had to get even after all those strict, cold and normative attitudes we had been exposed to during our art education. Elisabeth Engen, Lillian Dahle and I studied furniture design together in Bergen. For us postmodernists, the assertion that form must absolutely follow function was not just untrue but also wrong. A number of utterances and forms out there in history had been discarded as impure and as decorative crimes, stories that no one had properly listened to. We interpreted colour, ornaments, decorations and qualities of materials as a part of the communications things brought with them from present times. For us, this purity and unambiguousness sounded like a speech from a bygone time. During the 1970s and 80s, the speech represented boring, run-down and unacceptable content. It was like a relationship that you have grown out of or possibly never even felt like you belonged to.

Some things that belong to a particular time and that make up our lives are unchangeable. Other things are volatile, unpredictable and constantly changing, always on the lookout for something else. 
Constancy and change means that something remains throughout change, writes Christian NorbergSchulz in the introduction of his book Stedskunst (1996).

In his book, Norberg-Schulz writes about the everlasting relationship between man and his surroundings but acknowledges that they are relations that must be interpreted again and again (1996, p. 7). According to him, constancy and change contain all our possible conditions, both the given and the changeable. To be able to add adjustments and investigations as well as bear with the weight of such a re-interpretation, we must "listen" to the time we live in with open and undaunted senses. We must have the will, courage and capacity of implementation to develop our own expressions of our time and improve what we find wrong, humanised and imprecise. The book Courage to Create by the American psychologist Rollo May became a cult classic amongst artists and creatives during the 1980s (1975). May managed to put into words the risk of "being totally involved, yet attentive to the possibility that we might be wrong" (1995, p. 19). The paradox of courage is that it is accompanied with the anxiety of being mistaken; sleepless nights are never far away. May wrote about how this applies to all of mankind, not just artists. He encouraged us to commit to our imagination and implement what art historian Anniken Thue described in a catalogue from 1986 as "furniture fantasies and fantastic objects". ${ }^{3}$

My colleagues in the 1980s were Elisabeth Engen (her work: figure 4) and Lillian Dahle (her work: figure 3) They worked with wood in different ways to me, and with a closer connection to traditions of the craft, finding their expressions more closely connected to the actual materials themselves.

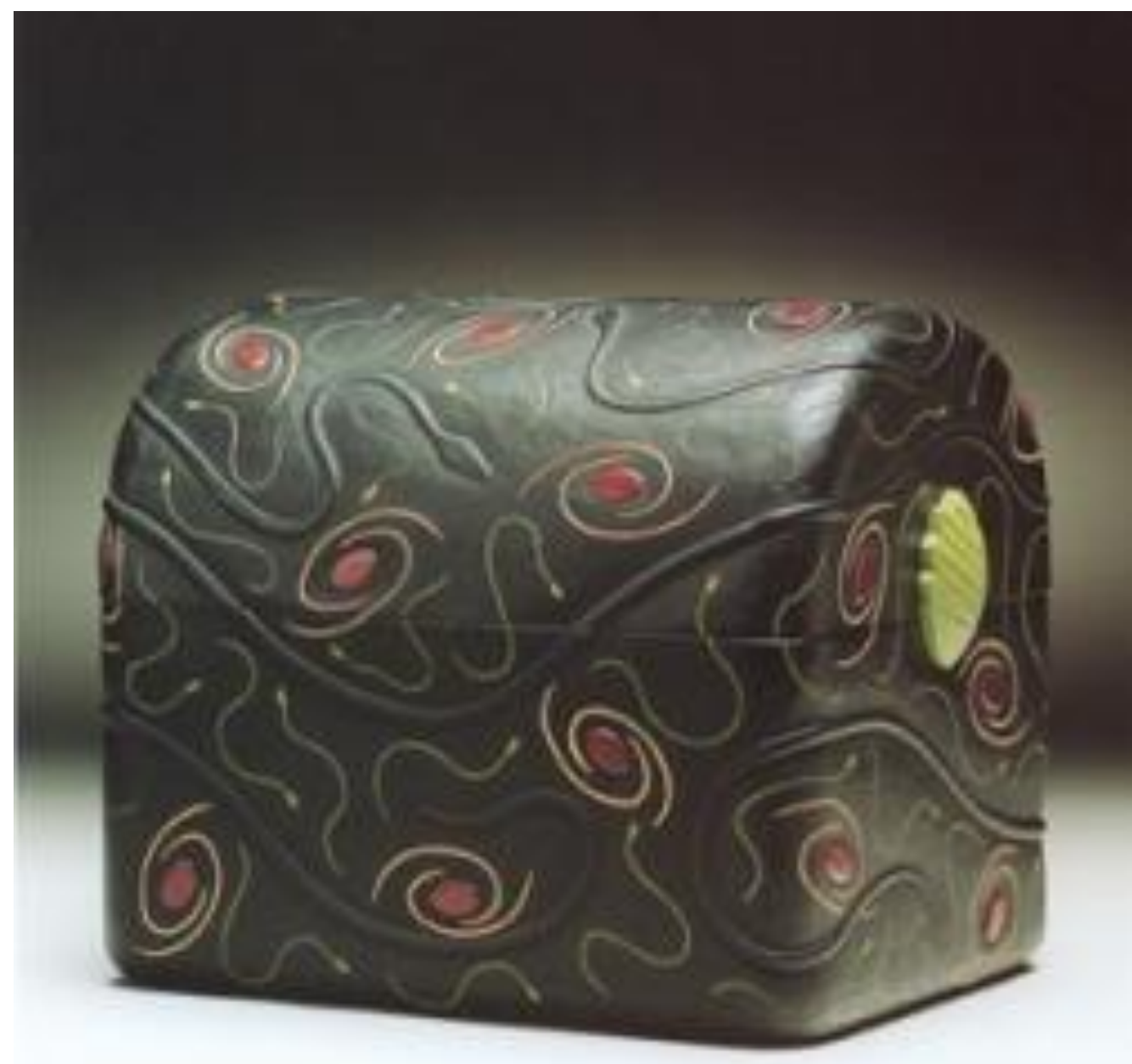

FIGURE 3."Heaven-earth" Small casket 1989 @ Lillian Dahle / BONO. Source: http://www.lilliandahle.no/ (03.04.2018). Published with the artist's permission. Photo: Pål Hoff. Reproduced with the artist's permission. 


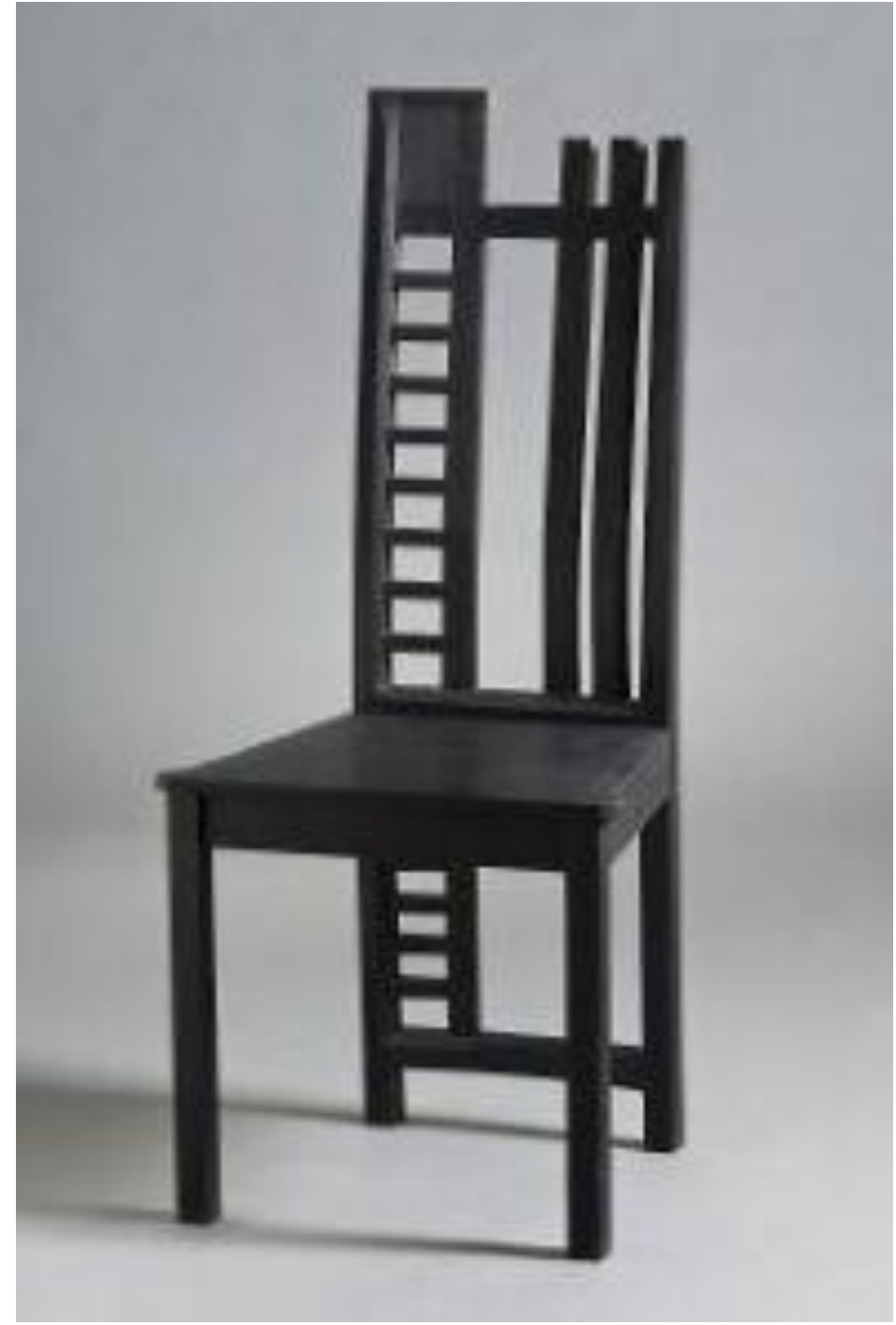

FIGURE 4."Punk Furniture" PE. (C) Elisabeth Engen / BONO Source: https://www.nasjonalmuseet.no/en/collection/object/OK1989-0094. Published with the artist's permission. Photo: Nasjonalmuseet.

In my own work, wood was more of a raw material to be built and joined in rational ways. An infinity of imitations and lush floridities have been made: fluorescent 'stone walls', turning spiers, worked surfaces and areas where different qualities were forced into colourful fellowship, built and interpreted by memories and sensations. Thoughts and emotions about colour and form were reborn into new narratives of acrylic, steel-plastic and thick layers of paint. Experiments were ongoing in our working partnership. This was much to the shock and horror of all kinds of purists, and the modernists' strict and normative view was given its deathblow. Out in the world, many have oriented themselves in the same landscape, such as the well-known Italian designer Ettore Sottsass and his Memphis-group. They designed the patterns of Formica and other design objects that were industrially produced. But we made our things by hand and had full control of our own workshops at our own expense and risk.

In my material-based reflections about the 'speech of things' was also a type of ironic humour. What I found especially funny was imitations of imitation. The anchor of authenticity and originality was completely rejected and made fun of. The idea of a pure material that safeguarded the unambiguous and rational function was done with. Imitations and loans were about bringing something back, investigating it once more with a particular view into form, colour and surface. The contemporary judges of taste, who were floating in the wake of modernism, tended to look down on and diagnose our utter- 
ances as 'decorative'; this criminal, ugly and inferior luxuriant that could be traced back throughout my irreverent messing up of all clean and pure. The spectators' interpretations were often steered by a lack of acceptance of knick-knacks and chit-chat. Any intimation of the function of things was judged in line with Kant's tastes and overruled as ugly. My works were full of exaggerations and rabid claims. To soak a mahogany surface with thick-flowing, cobalt-pigmented paint was a deliverance dripping of materiality. You use what you have and do as you please, with no 'master' looking over your shoulder. Imperfect from a craftsman's point of view: home-welded iron fittings in a rubbing disharmony with pastel colours for decorative purposes, hazel twigs and cow leather cushions. However, Seating furniture for the culturally advanced (1982) was purchased and still lives a quiet life in one of the country's best-furnished homes. As the 2000s continued, our free-spoken expressions still produced a reaction. Especially from certain art historians, particularly the Swedish and Danish ones, as Jorunn Veiteberg writes in her article Barbaric tendencies (2004). Veiteberg refers to French sociologist Pierre Bourdieu's definition of barbaric taste when she writes about the difference between "the two tastes", which she refers to as different cultures. "What is valued in art has value in everyday life. The barbaric taste likes vibrant colours and things with a sensory appeal and is not afraid of sentiment or pathos," she says (2004, p. 81). She claims that the reason Norwegian artists shook the other Scandinavians lies in our culture. The "barbaric tendency" lives and thrives in the close relationship many of us have to peripheral and scarce folk traditions and wild nature, far away from the avenues of the Swedish and Danish bourgeoisie. Yet, when at public get-togethers, I often meet my works interpreted and exhibited fore mostly as functional objects. My "barbaric" fantasies about things in their own right and speaking subjects are reduced into harmless and almost futile curio cabinets, such as in Store norske leksikon [The large Norwegian encyclopedia]. If Silver birch for the asphalt jungle (figure 5) was shown in a similar manner, it must be to reduce the sensory, poetic and sentimental that this thing speaks of.

The birch pictured above is imitated. Its core is wood and its surface is built from steel-plastic and paint. The crown is adorned with aluminium leaves and acrylic paint. It has an inner space that one can carefully open up and close.

In 1985, a selection of my works was displayed at the international exhibition Homo Decoransthe decorating human at Louisiana outside Copenhagen, alongside works from the Memphis-group and a number of other contemporary artists, designers and architects from around the world. At this point a comprehensive movement has developed. Its form reflected many modes of expression and was at least something with a more comprehensive content than modernism's ascetic mirroring of function. It was described as "critical design" or "radical design" in Europe (Hauffe, 1996). My distinctive career as a designer progressed for a number of years with many exhibitions and commissions. Elisabeth Engen and Lillian Dahle are still working on their own. Towards the end of the twentieth century, globalisation and internationalisation eventually led to a launch of competition against poorer countries. This again, led to a wretched situation when it came to working with crafts and material-based things. What Bård Breivik named "a human and cultural intelligence" was on request for tender and pulverized into the currents of globalisation at the same time as, according to Svendsen, the field of art was discontinued. Art became theorised and removed from the concrete by letting the idea or concept carry the meaning. The continuation is difficult to distinguish, as today digitalisation and computer technology challenge our occupation with "materials, time and space", writes Dag T. Andersson (2001).

Technology's pervasive impact on man's relationship with the world progresses unscrupulously. Not only the arts changed due to technical innovations, but our opinion of matter, time and space became something else, Anderson writes. New technologies make it possible to exceed the limitations set by the materiality of things. By violating the remoteness of things, technology invades the very nature of them (p.33) (...) things lose their aura when the invasion of technology destroys their remoteness, when the ability to reproduce robs them of their autonomy and their unique character, he continues in his interpretation of Walter Benjamin (2001, p. 35). Benjamin considers the aura to be a historical phenomenon that must be understood in the context of how humans' relations with the world have historically changed" (or in time, as I understand it). The aura protects the intrinsic value and individuality of things: It is a question of whether man's individuality is as threatened in a society where things are reduced to goods, says Andersson (p.35). 


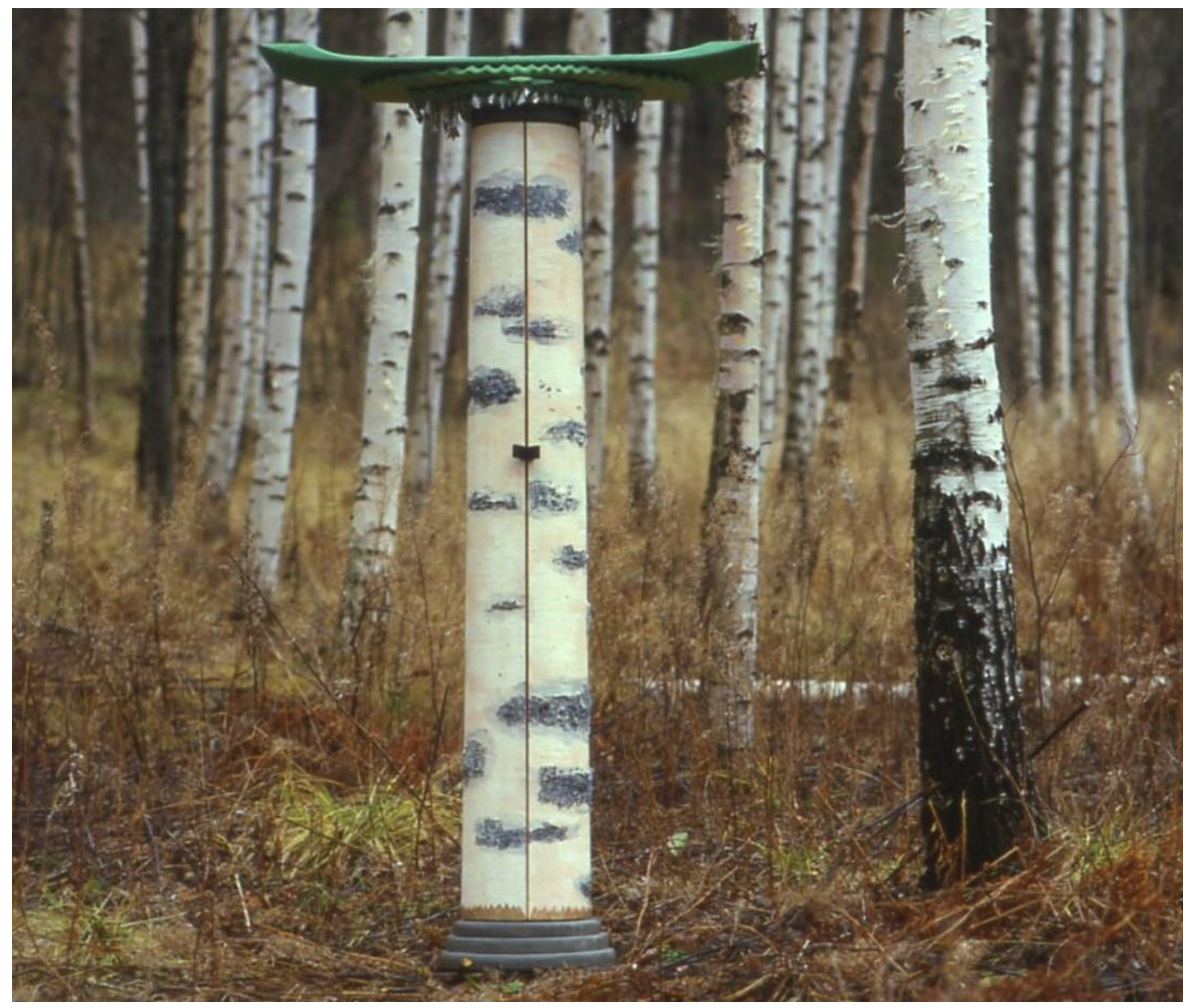

FIGURE 5. "Silver birch for the asphalt jungle" 1986.P.E. Denmark. Source: The artist's collections (C) Liv Mildrid Gjernes / BONO. Photo: Rolf M. Aagaard for Aftenposten, 1987.

During the process of restoring my swanky table, the thin teak veneer that covers the tabletop has been sanded so much that it is now worn down. When the consistently precious tropical wood appears as a shield and stuck on a wood board, the quality of material is dramatically reduced. In these days, tabletops given a name such as 'Ash', 'Oak' or 'Teak' are made from plastic laminate. They are photo reproductions of the relevant materials, embossed and transferred onto plastic veneers, and bonded to a stable sheet of material in the appropriate thickness. Completely maintenance-free and stable, it is a dead copy of the living. Plastic is plastic, and in laminate it appears to be the king of all imitations. Only those who know the sound, fragrance and taste of wood will in most cases detect the difference. The imitation of material is so well done that even a cabinetmaker might have to whittle or bite it to discern if it's counterfeit.

Veneers can be cut into thin layers from all sorts of wood. 'Images' formed by weaving different colours and wood varieties into intricate patterns are called intarsia. Hardening oil salvaged the remaining 1-2 mm of thin, peeled veneer on my battered and sanded table. Originally, the surface was most likely confirmed with a highly polished cellulose lacquer, which in its time created a smooth and shiny layer over the precious wooden surface. Well, until someone who has a strong drink and spills a little of it. The cellulose lacquer was soluble in spirits, and this would soon create rings and blemishes on the shiny surface. Eventually, plastic lacquer was invented. It withstands alcohol and most chemicals as it cures into plastic, just like wood glue does. The plastic coating does not understand that the wood is living matter. A small notch or crack in the varnish is enough for any moisture to reach the wood. Wood 
will, in keeping with its nature, swell, and the varnish will crackle. This problem particularly arises on soft woods, such as pine. The next solution was therefore to give the entire surface a coating of plastic. Wood was photographed and recreated in thin plastic flakes, ready and self-sufficient in its counterfeit form.

Within the traditions of furniture cutters, horn glue, or hot glue was used. Horn glue is organic and after it has hardened, it can be turned into liquid again, allowing parts to be disassembled with the help of heat. It's the drop in temperature that causes it to harden. The possibility of being able to replace, repair and correct parts allows for a longer lasting object. Today, the plastic product, glue, is also used. It cures as the moisture in it evaporates and becomes an unchangeable plastic. Once this has happened, there's no going back, and the piece of furniture cannot be dismantled without ruining the work. Anything that can be used can be discarded. Wood glue or PVA glue consists of plastic particles and cures as the wood and air in the room draws in the moisture of the glue. This plastic glue is the grief of conservators. Woodwork glued or veneered with old-fashioned glue consisting of horn/hooves/ organic material can be salvaged. Since horn glue can be reheated and re-melted, the parts may be carefully taken apart to remove a woodworm-infested part and replace with a fresh piece. Just as gently as removing the old piece, a new piece can be added before glued together.

The slender wood table legs with brass extensions on my little reclaimed table are painted black. The underside of the furniture board that makes up the tabletop looks to be covered with flame-birch veneer. Tropical woods were readily available in the 1960s. During my crafts education in the mid-1970s, we worked exclusively w Norwegian woods. The warehouse probably had the occasional teak plank, yet the main supply was first-grade carpenter pine of a quality that you have to go to specialist sawmills to get your hands on these days. Formica, the definitive plastic material that was glued to an underlying sheet with a contact adhesive or synthetic resin adhesive, was also invented in the $1950 \mathrm{~s}^{4}$. The underlying sheet was chipboard and consisted of wood shavings and glue mixed together into a mass that was pressured and hardened into sheets of low-tensile dead material. Formica solved the problem of surface durability, since it consisted of plastic that tolerated both stiff drinks and other strong beverages. During my childhood in the 1960s, the old long tables were eventually replaced with modern Formica-laminated chipboard boards on steel legs, in addition to the living room's coffee table in the wood type teak; shipped in from the tropical latitudes of the Norwegian merchant fleet.

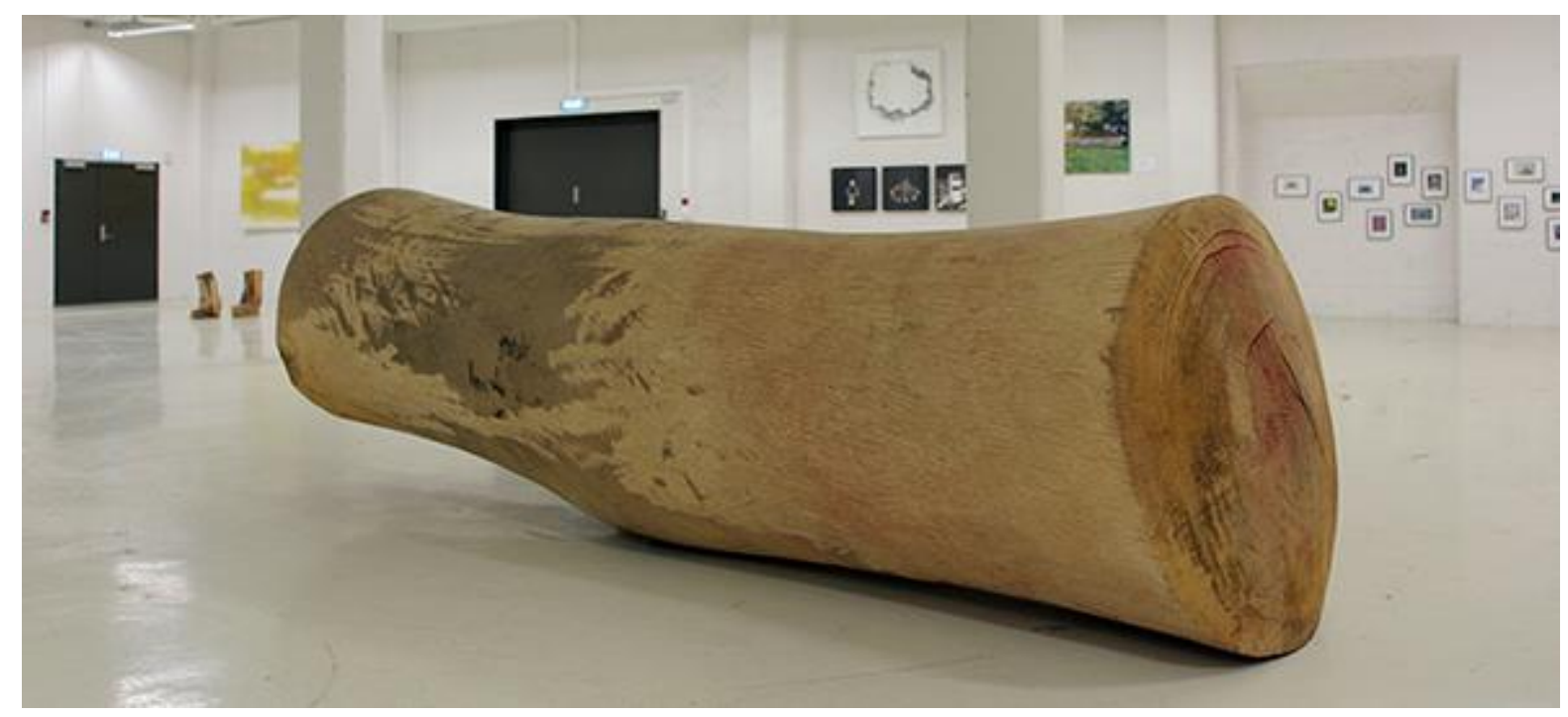

FIGURE 6. "The Oak Place". Leirdal 2008. Source: http://www.erlendleirdal.com/ (03.10.2018). Published with the artist's permission. Photo: Erlend Leirdal.

The Oak Place is the name Erlend Leirdal has given to the wood trunk he exhibited at the Trøndelagsutstillingen in 2008 (figure 6). An oak tree trunk: big, heavy and resting in its own strength. It just lies 
there. Throughout the 2000s, the expressions of materiality have moved further away from any interpretation of function and utility, and back to oneself and its possibilities. One needs no other experience than touching it, leaning on it, smelling its scent and perceiving the timeless willpower the wood holds for our senses. I see a strong optimism in this expression.
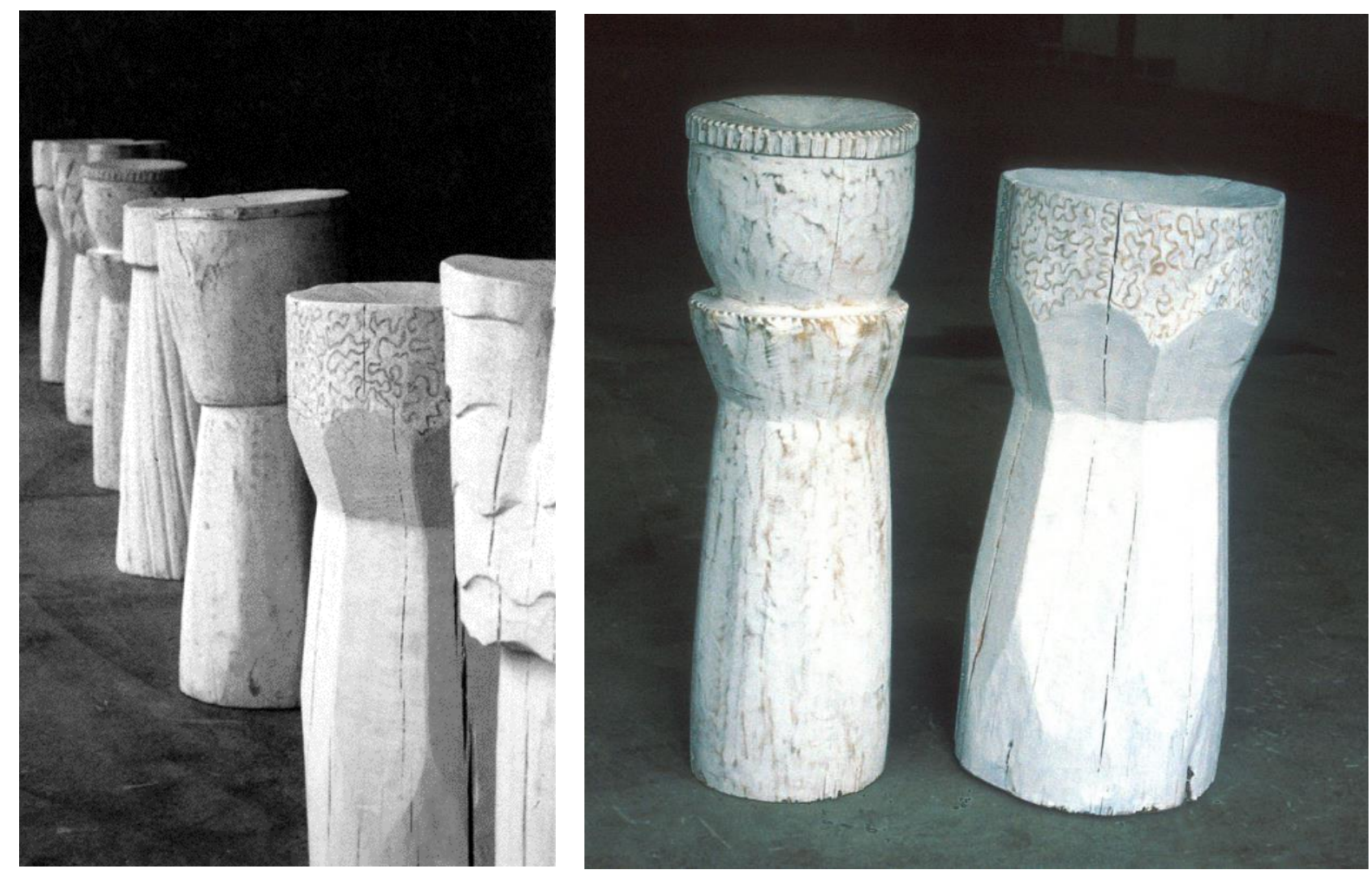

FIGURES 7 AND 8. "Furniture for wonder and conversation", 1997-2007. Liv Mildrid Gjernes. Source: The artist's collections. Photo: Liv Mildrid Gjernes.

For me, it was still about the problematisation of meaning and function towards the turn of the century, as shown in my series Tuntre (1997-2002). Tree trunks, equally remaining and surviving parts of something. They still have an "added value", as Austring and Sørensen call it (2006), even though it is simplified. What do visual expressions convey, regardless of time and technology? What meaning and values can we gather from their structures and autonomy? For the speech of things is addressed to us in a direct and completely physical way, in a communicating all their being, completeness and absolute presence. The way things meet our senses, the feeling of space, and the skin's sense for materials is something in itself. In our ears, materials have their own sound, as materials meet our aesthetic experiences with their offers to experience form. They blend in with our experiences and memories, and let their solid materiality frame our lives and tightly contain our history. Expressions in which form manifests meaning has followed mankind throughout time. As a historical phenomenon, and in present and concrete expressions, form and materiality have safeguarded and represented what Andersson describes as a completely sensory relationship to things (2001, p. 32). 


\section{REFERENCES}

Andersson, D. T. (2001). Tingenes taushet, tingenes tale [The silence of things, the speech of things]. Solum.

Austring, B. D. \& Sørensen, M. (2006). AEstetik og læring: grundbog om æstetiske læreprocesser [Aesthetics and learning: primer on aesthetic learning processes]. Reitzel.

Eliassen, K. O. (2008). Tingenes tale. Epistemologi, estetikk og eksistens hos Michel Foucault [The speech of things. Epistemology, aesthetics and existence in Michel Foucault]. Norsk filosofisk tidsskrift, 43(4), 272 283. https://doi.org/10.18261/ISSN1504-2901-2008-04-02

Landro, J. H. (2016). Bård Breivik om Bård Breivik. In J. Veiteberg \& R. Leppiniemi (Eds.), Bård Breivik. I'd love the key to the master lock (Vol. I). Fagbokforlaget.

Liv Mildrid Gjernes. (2019). In Store norske leksikon [The large Norwegian encyclopedia]. Retrieved November 6, 2019 from https://snl.no/Liv_Mildrid_Gjernes.

Loos, A. (1908). Ornament und Verbrechen [Ornament and crime]. https://de.wikisource.org/wiki/Ornament_und_Verbrechen

May, R. (1975). The courage to create. Norton.

Norberg-Schulz, C. (1996). Stedskunst [The art of making places]. Gyldendal.

Siesing, A. (2015). Svenska möbler: folkhemsform i ull, jakaranda, furu och bok 1949-1970 [Swedish furniture: folk home form in wool, jacaranda, pine and beech 1949-1970]. Bokförlaget Atlantis.

Svendsen, L. F. H. (2000). Kunst: en begrepsavvikling [Art: a concept settlement]. Universitetsforlaget.

Veiteberg, J. (2004). Barbariske tendensar [Barbaric tendencies]. Syn og segn, (1), 77-81.

\footnotetext{
${ }^{1}$ First published as Gjernes, L. M. (2019). Aarup 1960 and the poetics of materials. Conference Proceedings of the Academy for Design Innovation Management, 2(1). The article is republished with permission.

${ }^{2}$ In folk traditions, music was communicated without sheet music. Instead, musicians listened to performances and played later.

${ }^{3}$ The exhibition "Ting" Bergen + Festspillene in Nord Norge, 1986 was supported by Norsk kulturråd and Hordaland Fylke.

${ }^{4}$ Respatex (or Formica) is a previously registered Norwegian trademark of a high-pressure laminate of composite produced by Norsk Hydro from 1958 (https://no.wikipedia.org/wiki/Respatex 14.01.2017).
} 